\title{
REFLEXÕES E NARRATIVAS (AUTO)BIOGRÁFICAS SOBRE AS RELAÇÕES INTERGERACIONAIS: RESULTADOS DE UMA INTERVENÇÃO SOCIOEDUCATIVA COM MULHERES IDOSAS
}

\author{
REFLECTIONS AND (AUTO)BIOGRAPHY NARRATIVES ABOUT \\ INTERGENERATIONAL RELATIONSHIPS: RESULTS OF A SOCIO- \\ EDUCATIONAL INTERVENTION WITH OLDER WOMEN
}

Henrique Salmazo da Silva e Patrícia Grandino Junqueira

Universidade de São Paulo, São Paulo/SP, Brasil

\begin{abstract}
RESUMO
O objetivo deste estudo foi promover encontros de discussão sobre os relacionamentos intergeracionais com idosos participantes em um centro de convivência na zona leste do município de São Paulo/SP, com a participação de estudantes de escola pública da região. Tratou-se de uma pesquisa-ação, com objetivo de incentivar a reflexão dos idosos sobre as relações intergeracionais com base em seus dados autobiográficos. Os resultados da intervenção indicaram que houve avaliação dos atributos sociohistóricos e socioculturais do ciclo de vida, o que propiciou o protagonismo das participantes em relação ao processo de envelhecimento, trajetória de vida e compreensão das relações intergeracionais.
\end{abstract}

Palavras-chave: idoso; educação; ciclo de vida.

\begin{abstract}
The objective of this study was to promote discussion meetings about intergenerational relationships with older adults participants in a community center on the east of São Paulo/SP, with the participation of students in public schools in the region. It was an action research, in order to encourage reflection on the elderly intergenerational relations based on their autobiographical data. The results of the intervention indicated the evaluation of the attributes and sociohistorical sociocultural life cycle, which provided the role of participants in relation to the aging process, life story and understanding of intergenerational relations.
\end{abstract}

Keywords: elderly; education; vital cycle.

\section{Introdução}

Dentre os vários interesses que suscitam a pesquisa sobre desenvolvimento humano podemos destacar, na atualidade, as questões relacionadas a seus dois extremos: infância e velhice. À infância porque as sociedades ocidentais modernas têm depositado mais expectativas de que as novas gerações sejam capazes de conduzir a humanidade à superação de seus grandes desafios. Quanto ao envelhecimento, é urgente dedicar atenção em várias áreas do conhecimento a uma parcela da humanidade que vem se alargando, em razão das melhorias das condições de vida que garantem ampliação da expectativa de vida. Com escopo tão amplo, tomamos as relações intergeracionais como foco de investigação, pois interessa-nos reconhecer o potencial de acolhimento e transmissão entre netos e avós, de modo a identificar perspectivas educacionais geradoras de continência afetiva e de suporte geracional que os mais velhos possam prover aos mais novos, ao mesmo tempo em que, assim fazendo, observem-se o fortalecimento de vínculos e de resgate dos processos de filiação (Uhlenberg, 2000).

Em nossa "modernidade tardia" (Giddens, 1991), crianças, adolescentes e idosos têm muitas vezes seus direitos desrespeitados e são vítimas de hostilidade e violência. Por outro lado, e como forma de preservar a integridade e o gozo dos direitos desses cidadãos, pesquisadores e estudiosos sobre envelhecimento e educação têm proposto que a educação para o processo de envelhecimento é um dos meios efetivos 
para diminuir o preconceito associado à idade (Lopes, 2008). A Educação é também depositária das expectativas de garantia de melhores condições de vida para a infância e juventude, conforme já destacamos em outros trabalhos (Grandino, 2004).

Em outro eixo, a temática das relações intergeracionais, caracterizada por relações de trocas entre diferentes gerações, passa a ser cada vez mais desafiada no contexto da sociedade contemporânea, na qual são valorizadas as tecnologias, as atividades segregadas por faixa etária e que não propiciam as relações entre jovens e idosos (Ferrigno, 2003; Lopes, 2008). Nesse contexto, as relações entre as gerações precisam ser otimizadas com base em princípios relacionados ao respeito às diferenças, solidariedade e troca de experiências. Programas que favoreçam a integração entre jovens e idosos são escassos na realidade brasileira.

Estudos desenvolvidos com idosos, crianças e adolescentes têm destacado que é possível aprimorar o convívio, o capital social das relações humanas e o bem-estar entre as gerações. Para Ferrigno (2003) e Oliveira (1998, 1999), por exemplo, a interação efetiva entre gerações possibilitaria inúmeros benefícios, entre eles a coeducação entre os sujeitos, o respeito às diferenças e o exercício da cidadania.

Em outro estudo, Souza (2003) promoveu encontros intergeracionais entre três grupos de idosos da comunidade e entre nove grupos de adolescentes com idades entre 13 e 19 anos, afiliados a uma instituição formal de ensino. Os idosos participantes foram convidados a relatar as experiências de vida e a produzir reminiscências. Os encontros propiciaram a mudança de atitudes dos jovens em relação aos idosos e ao processo de envelhecimento. Alguns jovens relataram que os encontros tiveram implicações na melhoria e aprimoramento das relações que apresentavam com seus pais e avós, propiciando melhor entendimento e compreensão. Os idosos participantes do estudo relataram melhoria subjetiva no status da saúde e satisfação pessoal.

Oliveira (1998), ao investigar avós e netos pertencentes a classes econômicas baixas, sugere que os idosos são protagonistas de suas próprias reminiscências, tecendo sobre tempos que já não existem a não ser em lembranças. É sem dúvida a oralidade, assim como sugere o autor, que permite a união de próximos, mas diferentes, congregando a possibilidade de encontro entre o "fim do ciclo vital ao começo".

O presente estudo realizou-se por meio de encontros com idosos frequentadores de um centro de convivência localizado na zona leste do município de São Paulo. O local fica no entorno de uma escola pública que sediava uma pesquisa sobre o tema da Educação Comunitária, com vistas a potencializar outros espaços comunitários de promoção da educação. Utilizando a metodologia de histórias de vida e relatos autobiográficos, o objetivo do estudo foi o de proporcionar espaços de reflexão e ressignificação de etapas da vida junto aos idosos participantes e de incentivar a reflexão deles sobre as relações intergeracionais com base em seus dados autobiográficos. Com isso, buscamos verificar o potencial de acolhimento aos mais jovens que o grupo poderia exercer a partir de uma vivência potencializadora das trajetórias de vida. Nesse sentido, tratou-se de um estudo exploratório, de caráter participativo e vinculado à pesquisa mais ampla coordenada pela Profa. Dra. Patrícia Junqueira Grandino. Paralelamente, a pesquisa mais ampla desenvolvia na escola uma série de outras atividades de aproximação e valorização da diversidade e de reconhecimento da comunidade educativa. Ao final dos encontros propostos com o grupo de idosos, promovemos uma reunião entre eles e os adolescentes estudantes da escola pública sede da pesquisa. A Escola foi considerada um espaço rico para ações educativas entre alunos, comunidade, educadores e os próprios familiares, envolvidos no potencial de convivência existente entre as gerações.

\section{Método}

\section{Participantes}

Esta pesquisa foi desenvolvida na comunidade em um centro de convivência para idosos, vinculado à Secretaria Municipal de Assistência Social e ao Sistema Único de Assistência Social (SUAS) e localizado no entorno de uma escola pública da região de São Miguel Paulista, zona leste do município de São Paulo/SP. O centro oferecia atividades sociais e lúdicas com o objetivo de fortalecer a rede social e familiar dos idosos, cenário ideal para as intervenções propostas.

A população estudada foi composta por 15 mulheres da comunidade, frequentadoras do centro de convivência, com idade entre 60 e 80 anos de idade, rendimento mensal de um a dois salários mínimos, escolaridade entre zero e sete anos de estudo e de seis a dois anos de participação no grupo, familiares ou não dos alunos da escola e que aceitaram participar do estudo mediante esclarecimento prévio e assinatura do Consentimento Livre e Esclarecido. Foram 
garantidos todos os preceitos da resolução $n^{\circ}$ 196-96 da CNS do Ministério da Saúde, sendo a participação livre e espontânea. O projeto da intervenção foi apreciado e orientado por uma equipe de docentes da EACH-USP, respeitando-se os preceitos éticos de pesquisa. $\mathrm{O}$ estudo foi vinculado à FAPESP, no ano de 2006.

\section{As oficinas de relatos autobiográficos}

Para realização do estudo foram utilizados materiais e roteiros semiestruturados para realização da oficina, previamente preparados pelos dois autores do estudo com o objetivo de facilitar a participação do grupo e sensibilizá-los para a reflexão sobre dados autobiográficos a respeito das diferentes fases do ciclo de vida no contexto das relações intergeracionais.

Cada encontro contou com um material facilitador de discussão, consistindo em poemas, músicas, álbum de fotografias, dinâmicas de socialização, além de apresentação e discussão em grupo. O roteiro semiestruturado contou com questões sobre o modo de vida, reminiscências e a avaliação coletiva a respeito das mudanças sociohistóricas da construção das relações intergeracionais e do ciclo de vida.

\section{Procedimentos}

Foram realizados cinco encontros quinzenais, com duração de 90 minutos por encontro, no período da manhã. A periodicidade dos encontros foi estipulada com base na disponibilidade do grupo de idosas do centro de convivência. Houve a participação de todas as integrantes.

As atividades foram propostas e planejadas pelos autores com base na experiência acumulada em gerontologia, educação e intergeracionalidade. Os encontros foram liderados por um estudante de graduação em Gerontologia e por dois docentes da escola pública vinculada ao estudo, com formação em Pedagogia, supervisionados pela coordenadora da pesquisa central. As docentes da escola pública participaram como colaboradoras, revezando a participação nos encontros.

Dessa forma, os encontros tiveram como objetivos: (a) a produção de relatos (auto)biográficos e da trajetória de vida com base em encontros temáticos sobre relações intergeracionais, infância, juventude, envelhecimento e atividade de troca entre gerações (idosas participantes da pesquisa e alunos da escola municipal pública afiliada à pesquisa); e (b) a caracterização e reflexão conjunta sobre as concepções apontadas pelos participantes sobre relacionamentos intergeracionais, ciclo de vida e processo de desenvolvimento. Os temas dos encontros e o conteúdo geral foram:

$1^{\circ}$ encontro - "Relações Intergeracionais": o material facilitador do encontro foi o poema de Rachel de Queiroz intitulado "A Arte de ser Avó". A proposta foi refletir sobre as relações intergeracionais no ambiente familiar e nos espaços sociais e coletivos, propiciando a discussão coletiva sobre alternativas para abrir canais de diálogo entre as diferentes gerações.

$2^{\circ}$ encontro - "Infância e ser Criança": foi utilizado como material facilitador a música de Vinícius de Morais "Aquarela". As participantes foram motivadas a contar e comentar na atividade em grupo sobre a origem, as brincadeiras, as normas sociais que regiam os relacionamentos entre adultos e crianças, as funções desempenhadas no contexto familiar e as concepções vigentes sobre a infância, pinçadas de suas memórias sobre o tempo em que eram crianças.

$3^{\circ}$ encontro - "Adolescência e Juventude": objetivou promover reminiscências do tempo de adolescência das idosas e favorecer a discussão sobre os significados de ser jovem, os temas considerados tabus, os papéis sociais e as alegrias de ser jovem, no passado e na atualidade. Como estratégia de facilitação, solicitou-se às participantes que trouxessem materiais que representassem os significados de ser jovem e adolescente. As participantes foram convidadas a expressarem uma mensagem que o grupo, ao longo dos três encontros, gostaria de transmitir para as gerações mais jovens. Esta última atividade foi preparatória para o $4^{\circ}$ encontro.

$4^{\circ}$ encontro - "Atividade de Trocas Intergeracionais": o encontro teve a participação das idosas e dos adolescentes da escola pública da região. O objetivo do encontro foi promover a interação entre as duas gerações e incentivar, por meio de atividades lúdicas, o reconhecimento recíproco das etapas de vida, seus significados e a discussão das mensagens que o grupo de idosos elaborou no encontro anterior.

5 o encontro - "Envelhecimento, Saúde e Qualidade de Vida": foi promovida discussão grupal sobre como foi e como está sendo a experiência de envelhecer nos contextos sociais e familiares, objetivando refletir a respeito das concepções de envelhecimento saudável e as estratégias usadas para o bem-estar e satisfação com a vida. Após a discussão desses temas, houve uma avaliação geral dos encontros e encerramento das atividades. 


\section{Análise dos dados}

O relato autobiográfico foi a base para o material de pesquisa e análise dos dados, atribuindo aos sujeitos papel singular para a conexão entre os temas propostos e a apropriação do histórico de vida. Os encontros, ao invés de possibilitarem o registro fidedigno de como os fatos aconteceram e do valor das lembranças recordadas pelas participantes, apresentaram o papel de testemunhar a teia de significados que os sujeitos construíam ao citar passagens da própria experiência e de conteúdos do histórico de vida (Bosi, 1979).

A utilização do método autobiográfico neste estudo justificou-se na medida em que esse recurso viabiliza uma recapitulação do significado científico da subjetividade humana e atribui a ela um valor de conhecimento. Como abordagem investigativa, o método autobiográfico apresenta um caráter sintético (Ferrarotti, 1988), uma vez que por meio dele tornase possível reconhecer a mediação entre as condições macroestruturais determinadas pela história e pelas estruturas sociais e a infraestrutural, determinada pela dimensão da história pessoal.

Quando o indivíduo é chamado a falar ou escrever sobre sua própria vida, isso favorece a compreensão e articulação das experiências de uma pessoa (Holly, 1992) com seu contexto social e histórico. O relato autobiográfico significa o processo de contar a história da sua própria vida, e esse exercício de escrita possibilita uma reapropriação dos acontecimentos significativos de sua trajetória, ressignificando seu percurso, suas escolhas e seus propósitos, num processo autorreflexivo.

As narrativas autobiográficas tratam de uma práxis humana que articula experiência e conhecimento e que busca também articular, narrativamente, os momentos que fazem e desfazem o percurso de vida. Assim, carregam um potencial transformador. Essa possibilidade de transformação escapa à dimensão da compreensão meramente cognitiva, que se poderia pretender a partir da compreensão do profissional sobre as etapas e características de cada momento de sua trajetória pessoal (Grandino, 2004). Em razão dessas singularidades é que o método autobiográfico demonstra potencial promissor em estudos que envolvem a dimensão relacional entre indivíduos (Grandino, 2004).

Todos os encontros foram gravados. As narrativas foram fielmente transcritas e analisadas de forma qualitativa utilizando-se a análise temática proposta por Minayo (1994). Os depoimentos mais significativos foram agrupados em categorias de análise, apresentadas separadamente em cada encontro. Para preservar a identidade dos participantes, os depoimentos relatados foram acompanhados por nomes fictícios.

\section{Resultados}

\section{$1^{\circ}$ Encontro - Relações Intergeracionais}

As narrativas do encontro foram categorizadas em duas temáticas, o jovem como estranho e o jovem personificado, inserido no bojo das relações sociais e familiares. É a partir desse reconhecimento, feito pelo grupo, que os participantes refletem sobre as relações interpessoais e intergeracionais.

\section{O jovem como "o outro": estranhamento das ger- ações mais jovens}

Após a leitura do texto de Rachel de Queiróz, A Arte de ser Avó, Rosa se emociona e aponta que as relações de afeto e trocas também acontecem consigo mesma na relação cotidiana com seus netos. Apesar da relação de afeto, Rosa verbaliza que não consegue lidar com seus netos pelas diferenças culturais e sociais com as quais eles foram educados, o que na opinião dela dificulta o diálogo.

Seguida por outras participantes, o que parece emergir dessas falas é um sentimento de estranheza frente à postura dos mais jovens, um estranhamento que implica desrespeito dos direitos dos mais velhos. Violeta relata:

A juventude de hoje, eles têm que dar um crédito para nós que estamos nessa idade, porque a gente vai pegar um ônibus, eles passam pela gente, eles vão entrando, vão sentando... Eu fico pra trás, eu não vou ficar lá no meio... Oh... Sai pra lá, ou quando vê a gente fecha os olhos...

Os direitos reservados aos idosos, assim como sugere Neri (2006), contribuem em alguns momentos para a estratificação desse segmento perante as gerações mais jovens, causando situações de conflito ou de tutela sobre os mais velhos. Refletindo sobre como poderia melhorar essa situação, Lis assim acrescenta: "Trabalho e educação. O menino pode ser estudado como for, mas se ele não tiver um trabalho, entra aqui e sai ali. ... Eu acho!"

A participante parece indicar que a desvalia dos mais velhos está além de elementos socialmente valorizados na atualidade, como a educação formal. Indiretamente, ela faz referência à formação de valores, talvez mais frágil, na sua concepção, do que foi em gerações passadas. 
No papel de mulheres que já foram filhas, mães e atualmente avós, os depoimentos retrataram a dificuldade e o estranhamento que apresentam em conceber novas formas de estabelecer a educação dos filhos, assim como mudanças sobre os padrões e normas sociais que destoam do que foi estabelecido pelas gerações mais velhas na época em que eram jovens e construíram valores sociais. Os depoimentos de Rosa e Vitória-Régia reiteram essa posição:

"O que vocês estão tentando fazer é uma coisa lindíssima [referindo-se aos encontros], mas vai ser impossivel ... É difícil lidar com eles, é muito difícil." (Rosa)

"Fazem tudo o que querem ... é muito diferente a educação que nós tivemos com a educação que eles dão agora". (Vitória-Régia)

Hoje em dia os jovens não respeitam nada, eles são muito mal educados, não respeitam o idoso, pra eles tanto faz o idoso como não. A minha família é um exemplo disso, a minha filha é uma cobrinha. Eu tenho três netos, se eu falar alguma coisa para os meus netos ela acha ruim. Eu sou a mãe, eu cuido do meu jeito. (Petúnia)

A desvalia sentida pelos mais velhos se explicita na expressão "tanto faz o idoso como não". Assim parecem revelar que não veem reconhecida a experiência acumulada ao longo da vida.

\section{$\underline{\text { O jovem "personificado": respeito ao diferente }}$}

Ao final do encontro, Orquídea apresenta opiniões diferentes sobre temas relacionados à disciplina $\mathrm{e}$ à educação. A disciplina, vale lembrar, é sintoma da qualidade das relações, e aquele que se "indisciplina" quer também, inconscientemente, denunciar um malestar na relação (Grandino, 2001). Em relação ao grupo, Orquídea era uma das integrantes mais jovens e, talvez por essa razão, faça o contraponto: "Nem todos os jovens são iguais né? Tem muitos jovens rebeldes assim como tem outros mais pacificos. ... Rédea também não dá, né? Tem que soltar de vez em quando". (Orquídea)

Por meio dessa opinião, que foi relativamente contrária em relação ao que foi relatado no primeiro encontro, é possível perceber alguns direcionamentos que recebem as relações intergeracionais: quando se referiam aos jovens em geral, as idosas participantes apresentavam em seus depoimentos as diferenças entre os modelos de padrões e normas sociais atuais, considerados mais permissivos com relação à época em que eram jovens - mais rígidos -, assim como a dinâmica da indisciplina e da educação.
Por outro lado, ao se referir aos próprios netos, as participantes apontaram atributos positivos no papel de ser avó, incluindo a possibilidade de satisfazer a maior parte dos desejos dos netos, apesar de algumas serem cuidadoras e auxiliarem os seus filhos, tarefas que podem gerar um papel oneroso e estressante (Dias \& Silva, 1999). Existem, nesse sentido, duas diferenças substanciais: as gerações mais jovens em geral e as gerações mais jovens do círculo íntimo. Tais considerações apresentam aquilo que é incorporado de um discurso mais estereotipado na sociedade e que, olhado de perto, no bojo das relações íntimas, familiares, é reconsiderado.

\section{$2^{\circ}$ Encontro - Infância e os significados de ser criança}

As questões que nortearam as discussões do encontro foram o resgate da história pessoal, das origens familiares, das brincadeiras, de como as participantes faziam travessuras e dos tipos de relações estabelecidas com os seus pais, avós e gerações mais velhas. Utilizou-se a música Aquarela, de Vinícius de Moraes, como material facilitador. As narrativas foram divididas em duas categorias temáticas: a infância vivida e a infância atual.

\section{Infância vivida: travessuras, disciplina, rigidez e trabalho infantil}

Lis se mostra entusiasmada ao falar das travessuras da própria infância. Na sua narrativa se evidencia a imagem de uma menina sapeca e que não deixava por menos os prejuízos causados pelos seus colegas de classe da escola:

Professora ela está fazendo a rifa ${ }^{1}$. Rifa com grampos. A Professora disse: Pois ela vai ficar de castigo. Pois eu falei pra ele: Você vai me pagar, pagou, o castigo eu paguei caro, mas ele também pagou ... eu subi na calçada, peguei o tinteiro e quebrei em cima dos cadernos, peguei a caneta e quebrei e ó, dei no pé. Cheguei em casa, acabei de chegar e o moleque chegou atrás [risos]. Minha tia teve que pagar tudo e me deu uma bela de uma surra. Eu falei, não vai parar por aí, ele não vai mexer comigo, vai me pagar! (Lis)

escrevi um bilhetinho pra ele, a gente só se via na Igreja. E ela pegou o bilhete... Pra quê? Vocês vão engolir o bilhete! ... Ela me fez comer um cigarro, fez eu comer esse bilhete. Ela era severa demais! Ela disse: Você vai comer esse bilhete. Eu disse: Sem água [risos]. Ela disse: Não quero saber, vai engolir, mastiga e vai engolir. (Lis) 
No depoimento de Lis, a disciplina remonta à experiência vivida, só que, dessa vez, pela perspectiva de ser criança. No encontro anterior, quando as participantes foram incitadas a falar dos mais jovens, sugeriram a disciplina e o controle como algo que falta nas relações entre os adultos e jovens. Em seu depoimento, Lis destaca a severidade da tia, que pune através da agressão física. Na época em que Lis era criança não existiam leis que assegurassem proteção integral e contra os abusos físicos. As crianças não eram reconhecidas como sujeitos de direitos, o controle e a punição eram vistos como valores válidos para a boa formação das crianças. A rememoração da cena também não indica qualquer ressentimento em relação à punição sofrida.

Nessa perspectiva, a atualidade parece marcada por um crivo diferente de gravidade atribuída às transgressões dos mais novos, embora tenham conquistado um estatuto de maior centralidade na cidadania. Destacamos, nesse sentido, o Estatuto da Criança e do Adolescente, por representar um avanço sobre o modo de conceber as disposições legais e éticas necessárias para assegurar a proteção e alguns direitos fundamentais, conteúdos que atualmente devem ser assegurados.

Ao se recordar da infância, Rosa lembra-se com satisfação da adolescência, da competição entre as colegas de escola e os tipos de punição exercidos pela professora: "Eu gostava das minhas professoras, de vez em quando elas faziam assim na minha cabeça ... [simulando uma pancada] Eu lembro da unha dela. Eu achava bom, eu gostava, você vê agora, Deus o livre!" (Rosa).

Além da figura específica do adulto professor, é visível que a escola, de algum modo, participou e participa da vida das mulheres que relatam as experiências de vida. Como instituição que passa a ser coletiva e obrigatória a todas as crianças, a Escola passa a exercer um papel significativo sobre a educação, formação e para a construção de padrões subjetivos e individuais das gerações que viveram no século XX (Rego, 2003). Do ponto de vista da importância da escolarização, Dália aponta que as mulheres não tinham oportunidade de estudar porque os pais consideravam que esse seria um atributo masculino. A participante retomou os estudos na idade adulta, aos 42 anos: "Mulher não estudava, os pais não deixavam, quem só tinha que estudar era o homem. Eu mesma fiz a quarta série depois, com 42 anos" (Dália).

Embora a dificuldade de acesso à escolarização tenha sido marcada pela diferença de gênero, as memórias de infância das participantes são, no geral, positivas, mesmo quando mencionam o ingresso precoce no trabalho. Para Violeta, a infância foi um tempo muito bom. As relações com as gerações mais velhas, nesse sentido, contavam com a participação de atividades orientadas para o trabalho e de ajuda mútua para as tarefas do cotidiano:

\begin{abstract}
A minha infância, eu sempre trabalhei na roça. Já comecei por aí, oito horas da manhã levantar, fazer almoço, pegar a enxadinha, limpar a roça. E era um tempo muito bom, eu gostava. Eu frequentei pouco a escola porque não tinha como frequentar, não tinha condição de ir pra escola, tinha dia que não tinha nem uma folha de caderno pra estudar. Então eu estudei dois anos. (Violeta)
\end{abstract}

\section{Infância de hoje: tecnologias, escolarização e a ausência do brincar}

Algumas participantes reafirmaram, ao lado de Violeta, que a infância da roça foi boa e talvez melhor do que a de hoje, com o avanço dos produtos tecnológicos, trabalho dos pais, afiliação nas creches e com as novas formas de brincar:

[As crianças] Não sabem viver e aproveitar, eles só querem computador, jogo. Eles não sabem o que é pular uma corda, brincar! No nosso tempo a gente brincava na rua, de pega-pega, pular corda, hoje em dia não, as meninas não querem nem saber, só querem pensar em namorado. Eu com 12 anos estava brincando ... hoje em dia você não vê tanto isso... A infância de hoje em dia não tem tanta brincadeira. (Lírio)

"A infância não existe, com esse mundo de agora ... Por causa das drogas, as drogas estão dominando o mundo. É mentira? Está dominando o mundo. No nosso tempo não tinha isso ai" (Rosa).

Ao questionar a existência da infância, o grupo parece ter considerado as diferenças e feito uma avaliação que privilegia a infância de ontem, em detrimento da atual. A infância das idosas foi acompanhada pelo trabalho precoce, pouco acesso à escolarização e por relações de disciplina. Entretanto, na divergência que aparece nas falas finais, podemos perceber que há elementos que as fazem reconhecer modos diferentes, experiências distintas a cada tempo. Esse nível de reflexão é extremamente importante, pois para Ferrigno $(2003,2006)$ é a partir do reconhecimento da diferença que é possível ampliar a compreensão das relações intergeracionais e, ao mesmo tempo, ampliar o potencial de coeducação entre as gerações e a capacidade de aceitação das mudanças socioculturais. 


\section{$3^{\circ}$ Encontro - Adolescência e Juventude de outros tempos}

O encontro buscou resgatar eventos e fatos significativos da juventude. As reflexões tiveram como eixo norteador incentivar futuras questões para o $4^{\circ}$ encontro, propiciando a interlocução entre os jovens alunos da escola pública da região e as idosas do grupo. Destacaram-se na análise das narrativas duas categorias: a juventude vivida e idealizada e a juventude transgressora.

Juventude vivida e idealizada: trabalho, tarefas domésticas e início da idade adulta

Buscando compreender como foi a juventude dessas mulheres, os pesquisadores estimularam o grupo a verbalizar alguns dados sobre a própria história de vida e como avaliam a juventude de hoje e de ontem:

"Eu não tive juventude, tive que trabalhar desde cedo, eu tinha dez anos... Quando eu tinha dez anos subia naquela grade e fazia comida..." (Lírio).

Eu, com dez ou doze anos, eu morava no interior, eu rachava lenha, eu socava café no pilão, torrava café, eu fazia tudo isso também, fiz 70 anos semana passada, e aí? Hoje os garotos com 13, 14 anos não trabalham, podem estudar, têm mais mordomias. (Jasmim)

As falas como a de Jasmim, acima, podem ser marcadas pela noção de que a adolescênciaéum conceito atual e, no imaginário coletivo, representado por um tempo de ociosidade, em contraste com a memória do grupo que, em geral, iniciou cedo nos afazeres não apenas domésticos, mas de responsabilidades de trabalho e pouco acesso à escolarização. A ampliação do acesso à escola, bem como o aumento gradual do tempo dedicado aos estudos parecem ser percebidos como diminuição de responsabilidades dos jovens.

\section{Juventude transgressora: o reconhecimento de} tabus

Rosa, ao falar da sua própria juventude, avalia:

Mas como eu era danada naquela época, nossa! ... O onibus passava na minha porta e eu combinava com as minhas amigas, ah vamos no cinema lá pra cidade! ... A minha mãe não deixava de jeito nenhum! ... Eu não fazia nada de errado, eu era honesta. Só que eu ia e ela não sabia...

A proibição, de certo modo, não fazia com que Rosa deixasse de ir ao cinema. Para evitar conflitos com a mãe, combinava com as amigas de ir às escondidas. Nesse sentido, Rosa continua:
Na época eu tinha uma irmã minha, mais velha, que namorava. Então o rapaz vinha na minha casa, cumprimentava a minha mãe, o meu pai, e quando o namorado dela ia embora, a primeira coisa que o meu padrasto fazia era chamar algum irmão pra sair com ela [a irmã], era sagrado ... Eu fazia tudo aquilo que a minha mãe não gostava, eu era uma ovelha negra...

Rosa, se autodenominando a "ovelha negra", era uma pessoa que se diferenciava dos padrões e normas sociais exigidos pela sociedade em que vivia quando jovem. O fato de ir ao cinema escondida da mãe e de não querer se envolver com namorados logo cedo são fatores significativos que aparecem no depoimento da participante. Nesse momento, o pesquisador a incita a refletir sobre o que descreveu no primeiro encontro, a respeito da dificuldade que apresentava para se relacionar com os netos. O seu reconhecimento como jovem poderia auxiliá-la a exercitar algumas crenças e condutas da juventude dos dias de hoje.

\section{$4^{\circ}$ Encontro - Troca Intergeracional}

O encontro, dividido em dinâmicas e discussão em grupo, propiciou duas categorias de narrativas: apresentação inicial e papéis sociais no contexto das relações intergeracionais.

Apresentação e reconhecimento inicial: o outro como singular

Para favorecer o diálogo entre os dois grupos de participantes foi proposta uma atividade de apresentação entre jovens e idosos. Para tanto, o grupo foi dividido em seis duplas, cada qual composta por um jovem e uma idosa. Os participantes, ao se apresentarem, enfatizaram informações, como a composição familiar, idade, série escolar e algumas características pessoais.

Dália apresenta o adolescente Apolo:

Eles são em duas irmã e um irmão. São em três irmãos.... Todos os três estudam, diz que ele é obediente para o pai e pra mãe e eu fiz uma pergunta pra ele: Quando um jovenzinho fala para o pai e pra mãe que vai pra escola e fica fora da Escola, quem ele está prejudicando? Ele me respondeu: A si próprio. Gostei da resposta dele e gostei das entrevistas dele.

Apolo: "Essa é a Dália, tem 74 anos, trabalha em casa de família, cuida dos filhos dos outros... Não tem neto".

Dália: "Tenho filho adotado né? Cuido do filho dos outros".

Apolo: "Só perguntei se ela era casada". 
Confirmando a suspeita enunciada no encontro anterior, de que os jovens hoje não têm responsabilidade, a participante procura investigar justamente esse dado. Para Dália, Apolo é referenciado como um garoto que apresenta boas ideias, opinião que se centra no fato de que se apresentou como um bom filho e bom estudante, posto à prova quando Dália lhe perguntou sobre o que achava da atitude de alguns jovens que faltam às aulas e enganam os pais. Apolo por sua vez, parece estranhar o fato de Dália não ser casada e não ter filhos e nem netos. Tal reflexão compõe o eixo norteador dos papéis e das relações de trocas intergeracionais com base no relógio social: são esperados determinados comportamentos para cada categoria etária, como casar, ter filhos, estar na escola, entre outros (Debert, 1999).

\section{Papéis sociais no contexto das relações intergera-} $\underline{\text { cionais }}$

Após as apresentações, os participantes foram convidados a participar de uma dinâmica que consistiu em colocar nas costas de seis voluntários do grupo papéis com a inscrição de adjetivos, como "um pouco exigente", "carinhosa"; "rebelde". A tarefa dos voluntários centrava-se em tratar os demais com base nas inscrições que estavam afixadas nas costas de cada um, comprometendo-se a manter sigilo sobre o que estava escrito. Os demais participantes tiveram como tarefa observar para que, ao final do encontro, fossem promovidas reflexões com base nos papéis que foram representados pelos voluntários na dinâmica.

Houve timidez ao participar da atividade e alguns integrantes pareciam que não haviam compreendido o propósito da dinâmica. Rosa foi a primeira a abstrair a ideia e a começar, um a um, a abraçar os participantes. As outras participantes idosas, logo em seguida, também reproduziram este comportamento, olhando primeiro na inscrição nas costas e depois abraçando os outros participantes. Logo em seguida todos foram solicitados a expor o que sentiram ao participar da atividade:

Dália: "Eu observei ali que ele não é o que está escrito" [se referindo a Apolo que apresentava nas costas a inscrição: "um pouco rebelde']".

Crisântemo: "Não, mas ele não é rebelde [risos]".

Rosa: "Mas eu tratei ele como se ele fosse rebelde. Eu abracei porque o rebelde precisa de muito carinho, apoio e paciência!”.

As representações realizadas na dinâmica estimularam de algum modo o senso crítico dos participantes para afirmar e identificar-se ou não com os papéis que foram designados aos voluntários. Camélia se identifica com o papel com a inscrição de exigente e logo em seguida é interrompida pelo grupo, explicando que os papéis foram colados de forma aleatória e que não era o propósito rotular os integrantes. A discussão passa então a ser direcionada para as implicações que as características pessoais possuem na qualidade das relações entre as gerações:

Mnemosine: "Eu acho que acontece isso, se o avô sabe o que o neto vai falar, se ele for orgulhoso, rebelde, como escrito no papelzinho, eu acho que ele vai largar de mão, nem vale a pena falar!".

Camélia: Quando eu percebo que uma pessoa não foi com a minha cara, eu dou flores! E quando eu vejo uma pessoa rebelde, eu gostaria de ajudar. A minha neta, por exemplo, eu quero ajudar ela, tenho que conversar muito. Eu preciso conversar com a mãe dela, ela é distante. Eu tenho doze filhos, eu tenho doze maravilhas, criei doze filhos ali com coragem, com carinho e com amor, depende da mãe saber sentar com o filho e conversar!

Os depoimentos de Mnemosine e Camélia são expressivos de que, no âmbito das relações, algumas características pessoais apresentam influência sobre o modo como as interações entre gerações se desenrolam. Mnemosine acredita que na relação entre avôs e netos, se o neto apresenta um atributo não desejável, como ser orgulhoso, o avô pode ter uma postura diferenciada com o neto e o "largar de mão".

Já Camélia, por outro lado, aponta que individualmente apresentaria uma postura de acolhimento e diálogo. Para a participante a presença de uma pessoa rebelde sugere a abertura de um canal de comunicação, de apoio. Ao criar os seus filhos, Camélia cita que os criou com muito amor e carinho, apresentando visões positivas sobre como são nos dias de hoje.

$\mathrm{Na}$ sua narrativa fica claro que a habilidade de diálogo entre os pais e filhos é uma dimensão imprescindível nas relações entre gerações, principalmente quando a temática refere-se ao universo de condutas e atributos pessoais, fatores que podem ser negociados pelo exercício da conversa e da escuta. Assim se evidencia a importância das trocas intergeracionais e da participação positiva que os avós podem ter na mediação de conflitos entre pais e filhos.

Após os depoimentos de Mnemosine e Camélia o encontro chega ao fim e algumas participantes, como é o caso de Rosa e Cravo, mostram fotos, guardadas em arquivos pessoais, de quando eram jovens, dos filhos quando eram pequenos, da família e dos netos. Alguns jovens, como Hera, ficaram impressionados em ver a 
possibilidade de Rosa recordar e registrar momentos tão significativos por meio das fotos.

\section{$5^{\circ}$ Encontro - Envelhecimento e Reflexões sobre a velhice}

$\mathrm{O} 5^{\circ}$ e último encontro tratou das discussões realizadas durante a trajetória do grupo e promoveu a reflexão sobre velhice e envelhecimento. $O$ grande desafio foi dimensionar a complexidade dos depoimentos e das reflexões promovidas. As narrativas foram agrupadas em dois segmentos: avaliação dos encontros e a velhice como etapa ressignificada e sociohistórica.

\section{Avaliação dos encontros intergeracionais}

Para dar início ao encontro, o pesquisador estimulou as participantes a avaliar os encontros e as experiências do contato com os adolescentes. Rosa, participante ativa de todos os encontros, inicia:

Eu gostei muito da menina que me entrevistou, foi muito bacana, de vez em quando eu vejo ela, ela me vê, mas ainda não nos vimos. Acho que todo mundo gostou. Eu gostei muito também, trouxe as minhas fotos, adorei, todo mundo viu.

No encontro anterior, ao final das atividades, Rosa e Hera (jovem participante), haviam combinado de se encontrar novamente. As duas participantes moravam muito próximas uma da outra, residindo nos arredores da comunidade da Escola à qual o presente estudo estava vinculado. Rosa, por não fazer parte do universo das relações familiares de Hera, talvez pudesse oferecer à adolescente novos modelos de identificação e de diálogo que os próprios avós e pessoas mais velhas da família não possibilitavam. Dália prossegue:

"Eu gostei... Eles [os jovens] queriam saber por que eu não casei. Insistiram três vezes... Eu falei, eu não casei porque eu não achei o homem que me interessava".

Rosa: "Mas Dália, ainda dá tempo de casar... Eu vi uma velhinha casando com 80 anos".

Dália: "Cada um é cada um né! Eu não ignoro não...".

A possibilidade de realizar um casamento na velhice causou risos e agitação entre as participantes. A insistência demonstrada pelo jovem, e até pelas colegas, sobre o não casamento de Dália sugere que a figura do idoso está associada à existência de uma grande quantidade de filhos, netos e uma história familiar derivada do casamento, fatores que outras participantes enumeraram com bastante frequência através das apresentações no encontro anterior.

\section{Velhice: etapa do ciclo de vida ressignificada e sociohistórica}

Depois de discutir temas da vida adulta e da velhice, como casamento e viuvez, as participantes do encontro foram divididas em dois subgrupos que tinham como meta defender opiniões contrárias relativas ao processo de envelhecimento. A finalidade da atividade foi promover reflexões sobre o processo de envelhecimento e sobre as próprias experiências em relação à velhice.

Rosa inicia a discussão com a tarefa de ser uma das porta-vozes do subgrupo que ficou responsável por enfatizar os aspectos negativos da velhice. Entretanto, ao iniciar o seu depoimento, relata que ficar velho é um prazer, atitude que é questionada pelos outros participantes, avisando-a que deve relatar os aspectos negativos:

Ah, eu achei assim, eu acho que nós temos que
agradecer a Deus que estamos vivos né? Ficar velho
é um prazer ... eu falei isso pra chegar agora ... Na
casa da gente somos obrigadas a depender de uma
filha... E leva um filho pra nós olhar com 10 anos, 12
anos e nós velhinha temos que ficar cuidando! Então
isso ai é ruim. (Rosa)

Eu acho que a velhice é ruim em partes, é porque a gente não tem mais a saúde que teria quando era mais nova, não tenho mais as habilidades que eu tinha quando era mais nova ... Não enxergo mais direito, não estou ouvindo mais direito, tenho um monte de coisa, muita dor... Nessa parte eu não minto, eu acho que nessa parte é ruim. Em questão da saúde mesmo. (Jasmim)

Eu comecei a viver quando eu peguei a terceira idade. Até quando eu não tinha a terceira idade era cuidar dos filhos, isso e aquilo tudo bem! Depois que chegou aos 65 anos aí que eu comecei a viver. Sair, passear, fazer grupos de amigas, igual a gente, isso é muito bom! (Lis)

"Agora eu vou falar o quê? Que eu fui contra elas? Elas são assim! Eu também sou feliz! ... A minha velhice é linda, maravilhosa, esta ai" (Rosa).

Ao falar dos aspectos negativos associados à velhice, Rosa e Jasmim se lembram dos atributos familiares relegados aos mais velhos, como a tarefa de cuidar dos netos, dos déficits sensoriais, da perda de habilidades físicas e funcionais, assim como da ocorrência de algumas dores que podem estar associadas ao aparecimento de doenças. 
Entretanto, de modo geral houve valorização dos atributos positivos da velhice. Os depoimentos que aqui estão sistematizados nos contam sobre a percepção de mulheres que estão vivenciando o processo de envelhecimento no ambiente dos centros de convivência, que em geral congrega uma série de atividades que se associam à velhice bem-sucedida e à criação de novos espaços para envelhecer (Debert, 1999; Ferrigno, 2003; Mercadante, 2002). Jasmim, ao avaliar os encontros, relata:

Ultimamente tem coisa que favorece a gente, a passagem de ônibus, essas atividades e espaços pra gente participar ... por isso agora está melhorando, mas já está melhor. Que nem os idosos de antes, foi pior pra eles, como pro meu pai, pra minha mãe, pros meus avós, não tinham essas coisas que hoje já tem. Mudou bastante e tende a melhorar! Isso é bom e pra gente é muito melhor né! Porque você tem até um tratamento melhor, você tem pra onde correr porque era mais dificil antigamente não é! Eu acho. (Jasmim)

No depoimento de Jasmim, em especial, a perspectiva histórica a que se refere, sobre as diferenças entre quando era criança e jovem, também é transposta para a fase atual da vida, a velhice. Se por um lado a trajetória de vida das participantes foi marcada pela presença do trabalho e da pouca escolarização, diferente do modo que atualmente se concebe o papel dos jovens, na narrativa de Jasmim a velhice oferece maior concessão de benefícios e oportunidades de participar de espaços que seus pais não tiveram quando ficaram idosos. A perspectiva de mudança e de melhorias configura em uma nova imersão com relação aos fragmentos iniciais do estudo, que apontavam a hegemonia de ideias que identificavam majoritariamente os mais velhos como sujeitos que sofriam penalidades nos espaços públicos e eram desrespeitados pelos mais jovens. Verifica-se que o potencial de mudança e a avaliação dos atributos sociohistóricos e socioculturais da etapa do ciclo vital que vivenciam surgem como fatores que possibilitam o protagonismo das participantes em relação ao processo de envelhecimento e trajetória de vida.

\section{Discussão}

Em consonância com outros estudos presentes na literatura, os dados e depoimentos sistematizados revelam que as relações entre gerações podem ser otimizadas por meio de iniciativas que levem em consideração o convívio, as trocas de experiências e o reconhecimento do outro como diferente, singular e sujeito portador de direitos (Ferrigno, 2003; Grandino, 2004; Oliveira, 1998, 1999; Souza, 2003).
Ao contrário das investigações realizadas por Ferrigno (2003) e Oliveira (1998), que se concentraram em investigar os benefícios das relações intergeracionais para o processo de coeducação dos sujeitos, este estudo explorou as relações entre gerações com base nas narrativas concedidas por mulheres idosas sobre os aspectos significativos da própria vida por meio de grupo de discussão e reflexão sobre as diferentes fases do ciclo de vida. Os encontros propostos, desse modo, priorizaram o processo de reflexão sobre como são as relações entre gerações nos dias de hoje e como eram na época em que vivenciaram a infância, a adolescência, a idade adulta e, por fim, quando se tornaram idosas.

As narrativas possibilitaram o desocultamento do papel histórico dos sujeitos, dimensão que valoriza a perspectiva histórica da trajetória de vida como um atributo inalienável e consistentemente acumulado no percurso de quem envelhece. As narrativas concedidas mostraram que infância e a juventude foram etapas marcadas pelo trabalho precoce, baixa escolarização e relações intergeracionais orientadas pelo pouco diálogo, presença de castigos físicos e excesso de regras baseadas no controle da própria conduta.

No presente estudo os dados sistematizados sugerem que as idosas vivenciaram um tipo de sistema educativo que valorizava a agressão física e enfatizava o estabelecimento de relações pouco democráticas entre as gerações mais jovens. Estes componentes são relevantes se considerarmos que as participantes, principalmente nos primeiros encontros, enfatizaram que a disciplina era uma dimensão que atualmente é com frequência negligenciada pelos jovens, pelas instituições e pelos próprios pais enquanto pessoas presentes na educação dos filhos.

Em outras palavras, apesar de as participantes terem vivenciado ambientes familiares e sociais dotados de controle da conduta e rigidez, nos dias de hoje acreditam que a amplitude das relações intergeracionais também poderia considerar a transmissão de valores orientados para o estabelecimento do respeito e do controle da conduta. Este tipo de contradição se situa, talvez, nas diferenças socioculturais presentes entre as gerações e ainda, pode ilustrar o trânsito a que muitos pais, educadores e gerações mais velhas se referem ao conceber que as relações devem se basear em atributos disciplinares diferenciados, mas que, ao mesmo tempo, enfatize as boas condutas e minimize os riscos da afiliação dos jovens na criminalidade e nos atos de atrocidade que a mídia e as comunidades se encarregam de difundir (Grandino, 2001, 2004; Lesourd, 2004). 
É interessante notar que os encontros possibilitaram refletir sobre as diferenças e ao mesmo tempo contou com a presença de participantes que questionavam as opiniões hegemônicas presentes na composição e formatação do grupo. $\mathrm{O}$ intercâmbio de ideias possibilitou o aprimoramento de concepções e visões das participantes em relação às gerações mais jovens. A postura do diálogo e a negociação dos interesses envolvidos nas relações entre gerações apareceram como depoimentos que podem ser indicativos de que os encontros proporcionaram benefícios para as participantes. Quando Rosa, no primeiro encontro, questiona a finalidade do grupo e relata que passou grandes dificuldades com os próprios netos também é um indicativo de que os encontros possibilitaram compartilhar as experiências e vivências em relação à temática estudada.

As limitações do presente estudo incluíram o número reduzido de encontros, a condução de somente um encontro de troca intergeracional e a ausência de uma avaliação objetiva em longo prazo, com o objetivo de medir o impacto da intervenção na relação com demais membros da família e comunidade. Acreditase que outras intervenções deverão considerar o perfil do grupo de idosos e estruturar os encontros com base nas demandas dos participantes. A proposta da atividade, embora tenha sido atrativa e com boa participação, pode ser melhorada com a inserção de intervenções voltadas para o ensino de tecnologias aos idosos e para a transmissão de conhecimentos e de um legado cultural aos mais jovens. As experiências aqui apresentadas podem ser replicadas por profissionais psicólogos, gerontólogos, da área de educação e da assistência social (Uhlenberg, 2000).

Além disso, de modo geral, pode-se depreender que a possibilidade de compartilhar experiências e de voltar a entrar em contato com passagens da história pessoal podem favorecer a ressignificação positiva do vivido e uma apropriação, em outros moldes, da trajetória pessoal. Desse modo, a referência positiva das participantes em relação às suas lembranças, bem como ao apreço pela experiência do envelhecimento podem ser consideradas como um efeito da participação nas oficinas, que permitiram o reconhecimento, a exposição compartilhada de experiências e a troca entre os sujeitos.

Acredita-se que a intervenção proposta poderá ser expandida para outros espaços na modalidade de intervenções grupais, planejadas para promover a reflexão e a participação de todos os atores sociais envolvidos: idosos, jovens, familiares e comunidade, aprimorando a noção de que uma sociedade preparada para a temática da velhice e dos temas associados ao ciclo vital humano inicia-se com a discussão nas comunidades, perpetuando a reflexão de maneira coletiva, comunitária e com a participação de variados atores sociais. O exercício de pensar junto e ouvir o outro tornaram-se fundamentais nesse processo, premissas básicas que, para Freire (1983), ajudam na formação da práxis humana, governada pelo pensar e agir. É necessário criar iniciativas que possibilitem um ponto de intersecção entre as mudanças que ocorreram e continuamente ocorrem com o conteúdo históricocultural guardado nas entrelinhas das narrativas concedidas pelas mulheres ao narrar a própria trajetória de vida.

\section{Nota}

1 Rifa é uma espécie de cartela em que as pessoas assinalam nomes ou números com o objetivo de concorrer a prêmios e gratificações. No caso de Lis, o prêmio eram os grampos.

\section{Referências}

Bosi, E. (1979). Memória e sociedade: lembranças de velhos. São Paulo: Editora da Universidade de São Paulo.

Debert, G. G. (1999). A reinvenção da velhice: sociabilização e processos de reprivatização do envelhecimento. São Paulo: Editora da Universidade de São Paulo.

Dias, C. M. S. B. \& Silva, D.V. (1999). Os avós: uma revisão da literatura nas três últimas décadas. In T. Féres-Carneiro (Org.), Casal e familia, entre a tradição e a transformação (pp. 118-149). Rio de Janeiro: Nau.

Ferraroti, E. R. (1988). Sobre a autonomia do método autobiográfico. In A. Nóvoa \& M. Finger (Orgs.), O método (auto)biográfico e a formação (pp. 17-34). Lisboa: Ministério da Saúde - Centro de Formação e Aperfeiçoamento Profissional.

Ferrigno, J. C. (2003). Coeducação entre gerações. Petrópolis, RJ: Vozes; São Paulo: SESC.

Ferrigno, J. C. (2006). A coeducação entre as gerações: um desafio da longevidade. In L. Pessini \& C. P. Barchifontaine (Orgs.), Bioética e longevidade humana (pp. 339-352). São Paulo: Centro Universitário São Camilo/Edições Loyola.

Freire, P. (1983). Pedagogia do Oprimido (13 ${ }^{\mathrm{a}}$ ed.). Rio de Janeiro: Paz e Terra.

Giddens, A. (1991). As consequências da modernidade. São Paulo: Ed. Unesp.

Grandino, P. J. (2001). Violências na escola e a dignidade dos sujeitos. ECCOS Revista Científica, 3(1), 141-151.

Grandino, P. J. (2004). A dimensão relacional na educação: análise de uma experiência formativa entre professores $e$ educadores sociais. Tese de Doutorado, Faculdade de Educação, Universidade de São Paulo, São Paulo.

Holly, M. L. (1992). Investigando a vida profissional dos professores: diários biográficos. In A. Nóvoa (Org.), Vidas de professores (pp. 1-15). Porto, Portugal: Porto Editora.

Lopes, E. S. L. (2008). Relações Intergeracionais. In A. L. Neri (Org.), Palavras-chave em Gerontologia (pp. 175-178). Campinas, SP: Editora Alínea. 
Lesourd, S. A. (2004). Construção do adolescente no laço social. Petrópolis, RJ: Vozes.

Mercadante, E. (2002). Comunidade como um novo arranjo social. Revista Kairós, 5(2), 17-34.

Minayo, M. C. S. (1994). Pesquisa Social: teoria, método e criatividade. Rio de Janeiro: Vozes.

Neri, A. L. (2006). Atitudes em relação à velhice: questões científicas e políticas. In E. V. Freitas (Ed.), Tratado de Geriatria e Gerontologia (2 ${ }^{\text {a }}$ ed., pp. 1316-1323). Rio de Janeiro: Guanabara Koogan.

Oliveira, P. S. (1998). Cultura e coeducação entre gerações. Psicologia USP, 9(2), 261-296.

Oliveira, P. S. (1999). Vidas compartilhadas: cultura $e$ coeducação de gerações na vida cotidiana. São Paulo: HUCITEC.

Rego, T. C. (2003). Memórias de escola: cultura escolar e constituição de singularidades. Petrópolis, RJ: Vozes.

Souza, E. M. (2003). Intergerational interaction in health promotion: A qualitative study in Brazil. Revista de Saúde Pública, 37(4), 463-469.

Uhlenberg, P. (2000). Integration of old and young. The Gerontologist, 40(3), 276-279.

Recebido em: 25/07/2010

Revisão em: 09/10/2011

Aceite em: 15/11/2011
Henrique Salmazo da Silva é Gerontólogo. Bacharel em Gerontologia pela Escola de Artes, Ciências e Humanidades da Universidade de São Paulo e Mestre em Ciências pela Faculdade de Saúde Pública da USP.

Endereço: Rua Felipe Bonani, 59. Jd Iguatemi. São Paulo/ SP, Brasil. CEP 08372-040. Email: henriquesalmazo@yahoo.com.br

Patricia Junqueira Grandino é Psicóloga. Mestre e Doutora em Educação pela Faculdade de Educação da USP. Docente da Escola de Artes, Ciências e Humanidades da Universidade de São Paulo (EACH/USP). Email: patjg@uol.com.br

\section{Como citar:}

Silva, H. S. \& Grandino, P. J. (2013). Reflexões e narrativas (auto)biográficas sobre as relações intergeracionais: resultados de uma intervenção socioeducativa com mulheres idosas. Psicologia \& Sociedade, 25(3), 559570 . 